\title{
METHOD FOR LABORATORY TESTING RUBBER PENETRATION OF STEEL CORDS IN CONVEYOR BELTS
}

\section{Dariusz WOŹNIAK* Monika HARDYGÓRA}

Wroclaw University of Science and Technology, Faculty of Geoengineering, Mining and Geology, Accredited Belt Conveying Laboratory

\begin{abstract}
As steel cord conveyor belts are vulcanized during the production process, rubber penetrates into steel cords. It is a positive and a desired phenomenon allowing the belt to reach its required properties and ensuring its reliable and long operation on the belt conveyor. Advantageously, the rubber compound penetrating into the cord improves the strength of the cord-rubber joint by increasing the active contact surface of the two materials. This fact is of great significance in the view of the steel cord conveyor belt splicing technology, which relies on an adhesive connection between the cord and the rubber. Moreover, filling the inside of the cords with rubber protects against corrosion and has a good effect on their durability. The article presents a laboratory method for testing and evaluating the penetration of the steel cord with rubber. The method has been developed on the basis of numerous laboratory tests, which are also here described. The presented method is reliable and can be used for a broad range of cord diameters and designs. The proposal also includes a quantitative measure of the rubber penetration of cord and the criteria for its identification.
\end{abstract}

Keywords: conveyor belt tests, steel cords, steel wire ropes, rubber penetration, rubber-metal connections

\section{INTRODUCTION}

High-capacity, long-distance belt conveyors are typically fitted with steel-cord belts. Such belts may resist high tensile loads while showing limited elongation. The

\footnotetext{
* Corresponding author: dariusz.wozniak@pwr.edu.pl) (D. Woźniak)
} 
main load-bearing element of the belt is its core comprising steel cords vulcanized in rubber. The steel cord consists of several spiral strands twisted in uniform direction around the core. In turn, each strand consists of several wires helically twisted in one or more layers. The core of a steel cord used in a conveyor belt is typically also a strand, referred to as a core strand, and the surrounding strands are referred to as outer strands. The cord constructions most commonly used in conveyor belts include (Fig. 1): seven strands of seven wires $(7 \times 7)$, seven strands of nineteen wires $(7 \times 19)-$ in both cases one core strand is surrounded by six outer strands - and also seven outer strands of seven wires plus one core strand of nineteen wires $(1 \times 19+7 \times 7)$. Such cord constructions result in voids being formed between the wires and between the strands. During the vulcanization of a conveyor belt, the rubber compound penetrates into the cords and fills the empty spaces (Fig. 1c). It is a positive and a desired phenomenon. When the belt is operated on the conveyor, its cover is frequently damaged (cuts and punctures) and allows moisture to penetrate into the belt core. As a result, the cords are subject to corrosion (Błażej et al. 2018). Filling of the empty spaces in the cord provides a good protection against the spread of moisture and corrosion inside the cord. In addition, during the operation of the belt, the cords are subject to varying loads, which cause the wires and strands in the cord to slightly dislocate. The presence of rubber between the strands limits their direct contact, having a positive influence on the cord life (Bonneric et al. 2019).

a)

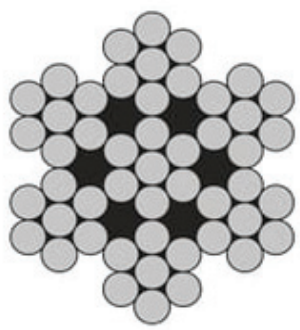

b)

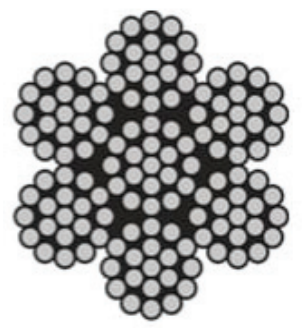

c)

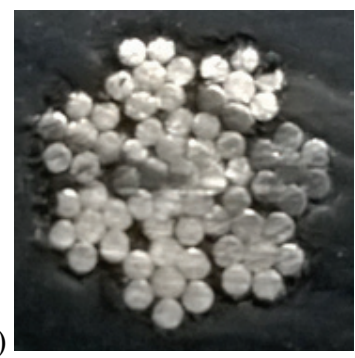

Fig. 1. Examples of steel cord constructions:

a) $7 \times 7$, b) $7 \times 19$, c) $1 \times 19+7 \times 7$ view of the cord in the belt

However, most advantageously, the rubber compound penetrates into the cord and thus improves the strength of the cord-rubber joint by increasing the active contact surface of the two materials. The strength of the steel cord-rubber connection depends on the amount of rubber penetrated into the empty spaces between the strands and between the wires. The technology of steel cord conveyor belt splicing relies in the first place on an adhesive connection between the cord and the rubber. Therefore, the strength, durability and aging resistance of a splice is crucial for the reliability of the conveyor belt (Hardygóra et al. 1999). 
Metal and rubber are materials having significantly different physical and chemical, as well as thermodynamic properties. Joining them is difficult and has become an object of interest for a number of research centers and manufacturers, mostly in the field of tires and conveyor belts. Effective joints between these materials depend on a number of factors, which are listed among others in the works of Rzymski et al. 2005, Jayaseelan and Ooij 2001, Rezaeian et al. 2012, Dobrotă 2013, Bajda et al. 2016. The strength, durability and aging resistance of a rubber-metal connection depends on the proper preparation of the metal surface and on the use of an intermediate layer having good adhesion to the joined materials. The surface is prepared mainly by cleaning it and changing its morphology in order to increase the degree of surface development and facilitate the dissipation of stresses on the border of the metal-rubber phase or the metal-intermediate layer phase. The techniques used for this purpose include mechanical techniques (e.g., sand blasting), as well as laser, physical and chemical (e.g., phosphatizing) or other techniques. The intermediate layer is a thin layer of another metal, or metal alloy coated on the surface of the metal element, or a layer of non-metallic adhesive substance (e.g., synthetic resins, silanes). In the case of tires and conveyor belts, good results are obtained by coating steel cords with a layer of zinc or brass. Another method consists in adding an adhesive substance to the rubber compound which is to be joined with the metal. The best results can be obtained if the two methods are used in combination, i.e., when a metallic intermediate layer is used together with non-metallic adhesive substances, the so-called adhesion promoters, which are coated on the metal surface or added to the rubber compound.

Therefore, the process of filling empty spaces of the steel cord with rubber during the vulcanization of conveyor belts is important for the quality of the belt. However, no standards have been yet established to aid the evaluation of whether and to what an extent the cord was penetrated with the rubber compound. Inspired with the idea of a method for testing adhesion between the rubber and the cords in accordance with ISO 7623:2015 and with the related experiences of the companies operated by Vattenfall, the authors of this article present a method and parameters for evaluating rubber penetration of steel cords in conveyor belts.

\section{RESEARCH METHOD}

The research method is assumed to consist in identifying force $F$ required to tear the core strand of a cord from the surrounding outer strands along a distance $L$ (Fig. 2a). The measure of cord penetration with rubber, and at the same time of the adhesion of the core to the rubber, is assumed as a unit tearing force expressed in newtons per one millimeter of the measurement length of the test specimen. Importantly, in every laboratory-test method the result should be firstly reliable, i.e., the parameter identified in the test should describe a particular required quality of the product, secondly useful, 
i.e., the test result should allow the evaluation of a particular phenomenon, and thirdly of an acceptable accuracy, repeatability and reproducibility. Therefore, at the outset consideration should be given to various aspects of the test procedure and their influence on the test result.

\subsection{THE TESTED OBJECTS}

The test specimens were provided by two conveyor belt manufacturers, and included a total of thirteen conveyor belt samples together with sections of new steel cords used in the belt production process. The new cord sections from a particular belt were described in a way which facilitated identifying the location of a particular cord in the belt.
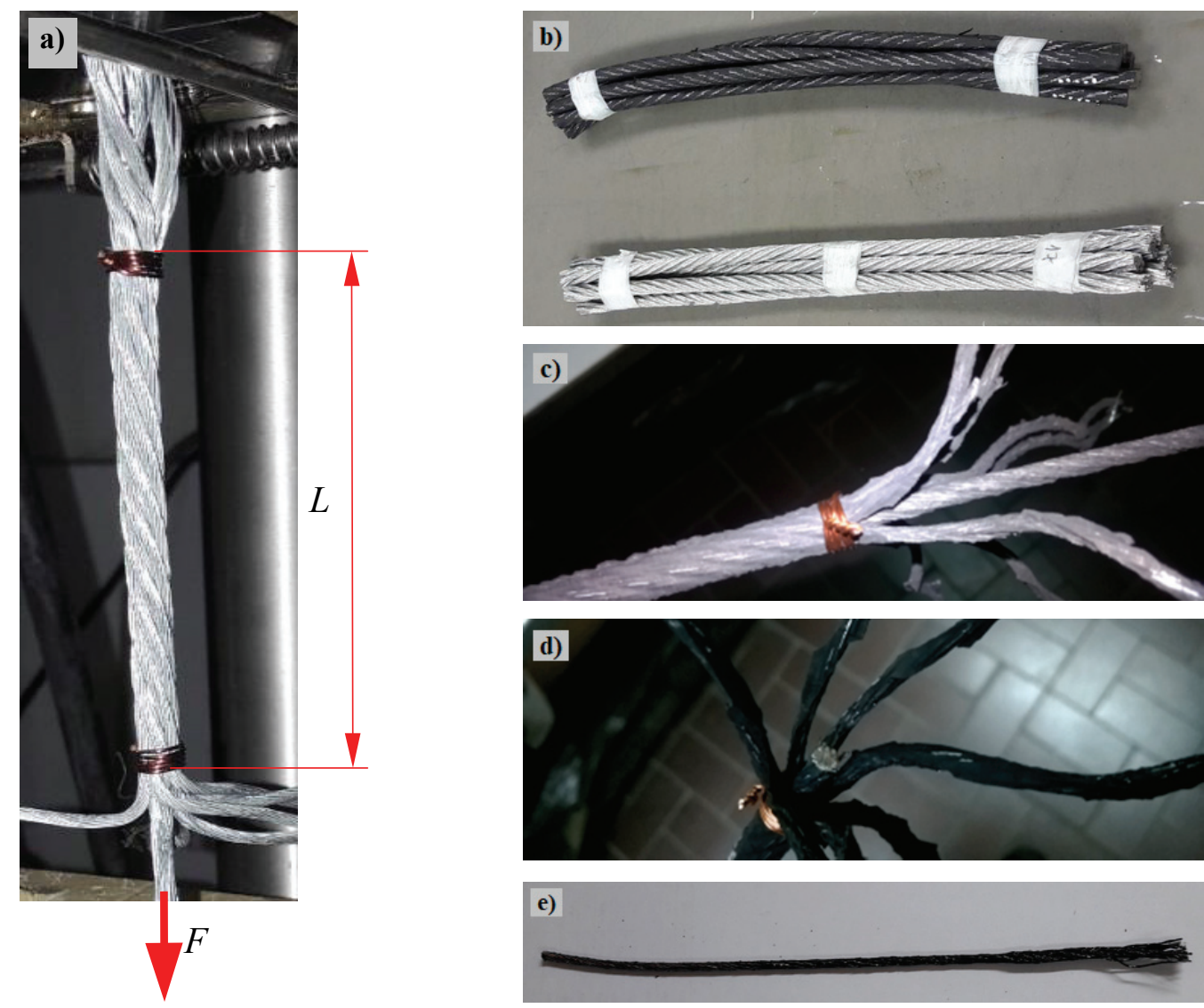

Fig. 2. Test specimen: a) a specimen during the test,

b) test specimens of new cords and of the cords obtained from the belt,

c) test specimen on the side of the core strand, d) test specimen on the side of the outer strands,

e) core strand after the test 
As a result, the cord could be tested both before and after the vulcanization process. The manufacturers of the belts used cords having two lay types, positioned alternately in the belt. The cords had SSZS and ZZSZ lays. The first two symbols indicate the lay of the core strand and the other two symbols indicate the lay of the outer strands around the core and the lay of the wires in the outer strand. The belts were manufactured with the use of various cord diameters and constructions, and four different rubber compounds. Table 1 lists the belts used in the tests, together with their cord diameters and cords, and with their rubber compounds.

Table 1. List of the test specimens

\begin{tabular}{|c|c|c|c|c|}
\hline Belt number & $\begin{array}{c}\text { Cord diameter } \\
{[\mathrm{mm}]}\end{array}$ & Cord design & $\begin{array}{c}\text { Breaking force } \\
\text { of cord } \\
{[\mathrm{kN}]}\end{array}$ & $\begin{array}{l}\text { Rubber } \\
\text { compound }\end{array}$ \\
\hline 1 & 3.2 & $7 \times 7$ & 10.5 & \multirow{7}{*}{ A } \\
\hline 2 & 3.7 & $7 \times 7$ & 13.7 & \\
\hline 3 & 5.2 & $7 \times 7$ & 26.4 & \\
\hline 4 & 5.4 & $7 \times 7$ & 29.1 & \\
\hline 5 & 6.8 & $7 \times 19$ & 41.2 & \\
\hline 6 & 8.2 & $7 \times 19$ & 57.7 & \\
\hline 7 & 10.6 & $7 \times 19$ & 93.5 & \\
\hline 8 & 5.2 & $7 \times 7$ & 26.4 & \multirow{3}{*}{ B } \\
\hline 9 & 6.8 & $7 \times 19$ & 41.2 & \\
\hline 10 & 8.2 & $7 \times 19$ & 57.7 & \\
\hline 11 & 6.8 & $7 \times 19$ & 41.2 & \multirow{2}{*}{$\mathrm{C}$} \\
\hline 12 & 8.8 & $7 \times 19$ & 66.0 & \\
\hline 13 & 6.7 & $7 \times 7+1 \times 19$ & 40.3 & $\mathrm{D}$ \\
\hline
\end{tabular}

\subsection{EXPLORATORY RESEARCH}

The analysis presented below is based on the results of tests performed at the Belt Conveying Laboratory, Wroclaw University of Science and Technology and of tests performed by students as part of their diploma dissertations (Pypeć 2016, Krakowski 2017). The cord tests consisting in tearing the core from the outer strands were performed for both the new cords and the cords obtained from the belts (Fig. 2b). Every test was performed on a minimum of five test specimens. The total number of test specimens exceeded two hundred.

Investigations focused on those aspects of the test which may have an influence on the test result. One of such aspects is the method of preparing the test specimen. Preparing the test specimen is the most time-consuming process, which is at the same time important for the accuracy and repeatability of the test. The cord obtained from 
the conveyor belt was cleaned from the rubber. In the next step, it was cut to a length which corresponded to the sum of the measurement length $(L)$ and the lengths of the two test specimen clamp parts $(2 \times 100 \mathrm{~mm})$. The cord along the measurement length $(L)$ was further protected against untwisting during the preparation of the clamp parts and the tests proper. Various protection methods were analyzed: seizing with wire, with a metal clamp or with a plastic clamp. The tests indicated that the best solution was to seize the strands with five turns of a copper wire $0.8 \mathrm{~mm}$ in diameter (Fig. 2a). The seizings are parts of the measurement length $L$. In the next step, the outer strands were untwisted on both clamp parts of the test specimen and the core strand was cut on one end, at a distance of max. $15 \mathrm{~mm}$ from the measurement length (Figs. 2c, d). The new cords were similarly prepared for the tests. The test specimen was placed in

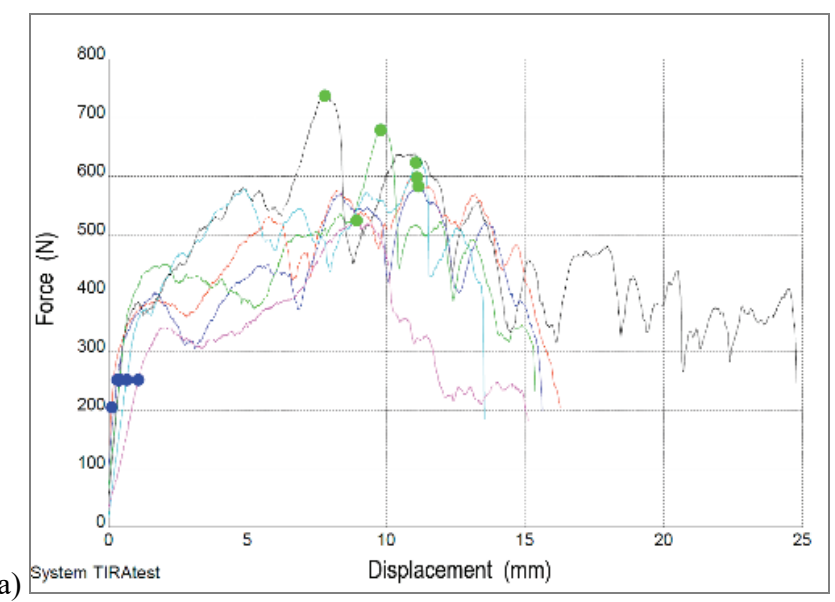

a)

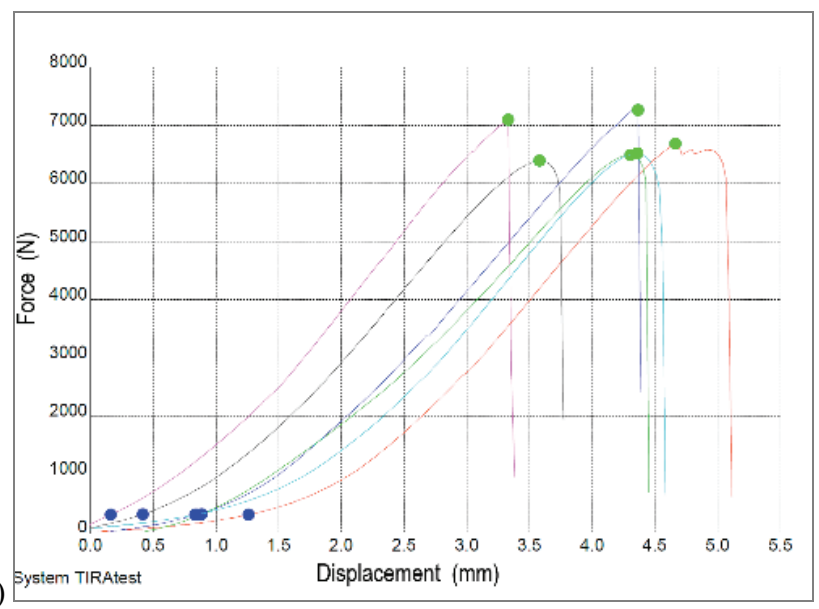

Fig. 3. Tearing force of the steel cord core from the outer strands: a) new cords, b) cords obtained from the belt 
the testing machine and the core strand was secured in a clamp on one side, while the outer strands were secured in a clamp on the other side. Special attention was paid to the clamping method of the outer strands, which when clamped should be in the shape of the letter $\mathrm{V}$, at an angle of approximately $15^{\circ}$. In the case of the core strand, on the other hand, the best clamping method is to use a rope clamp. The secured test specimen was subjected to a tensile load with the speed of $25 \mathrm{~mm} / \mathrm{min}$. Figure 3 is an illustrative graph of forces recorded during tests of new cords and cords obtained from the belt. The recorded force $(F)$ was the maximum force during the tearing of the core strand from the outer strands. The measure of the adhesion of the core strand to the outer strands is unit force $\left(F^{\prime}\right)$ expressed in newtons per one millimeter of the measurement length $(L)$.

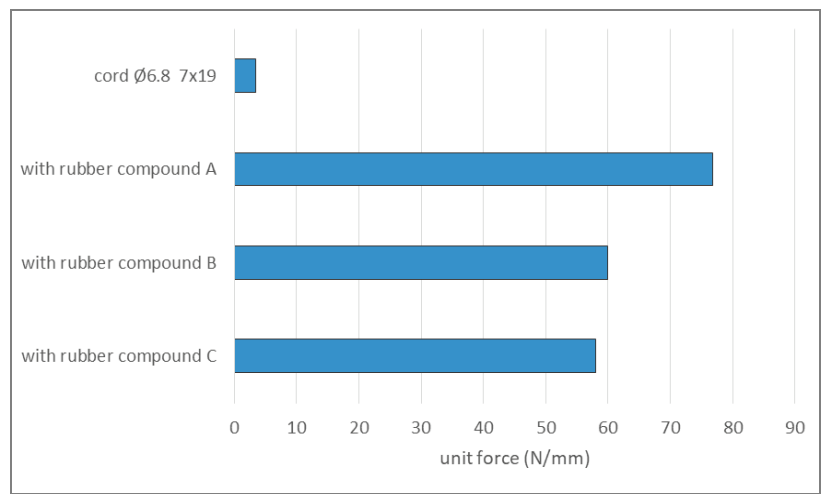

Fig. 4. Test results of the cord core adhesion to the strands for the new cord and for the cord vulcanized in various rubber compounds

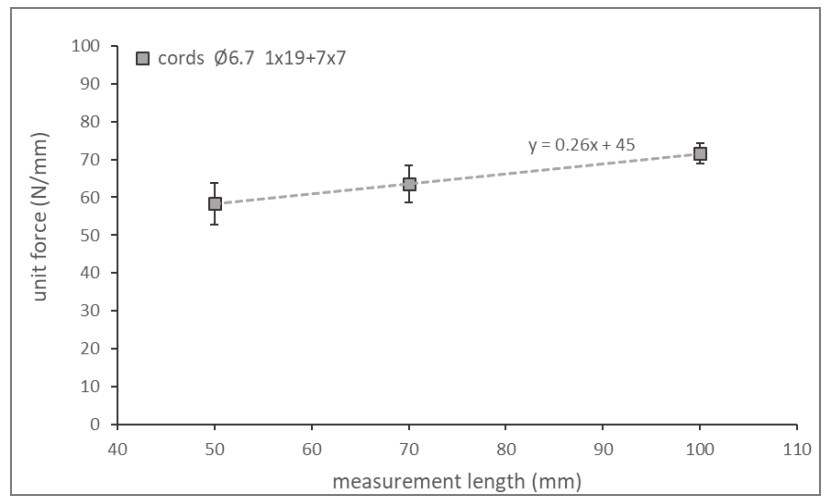

Fig. 5. Influence of the measurement length on the results of the cord core adhesion to the strands 
The tests were performed for a new cord $6.8 \mathrm{~mm}$ in diameter and a $7 \times 19$ construction and for the same cords obtained from three belts in which various rubber compounds were used. The results of these tests are shown in Fig. 4. In the case of the vulcanized cords, the unit force required to tear the core from the outer strands was over twenty times higher than in the case of the new cord. Also, the torn core strands were covered with a rubber layer along their entire length (Fig. 2d). The influence of the rubber compound on the test results was also observed. Therefore, the method may be certainly concluded to be reliable and useful in the evaluation not only of the cord penetration and fill degree with rubber, but also, to a certain extent, of the adhesion strength of the rubber-metal connection.

The length of the measurement section of the cord and its influence on the test results also required investigations. The tests were performed for cords having a $6.7 \mathrm{~mm}$ diameter and a $1 \times 19+7 \times 7$ construction, obtained from the same belt, using three different measurement lengths $L(50,70,100 \mathrm{~mm})$. The results of these tests are shown in Fig. 5. Observations indicate that the unit force required to tear the core strand of a cord from the outer strands indeed depends on the measurement length $(L)$. Increasing the measurement length $(L)$ results in an increased unit force. At the same time, the smallest measurement uncertainty (Fig. 5) was observed in the case of the result for the test specimen having the longest measurement length. For accuracy reasons, the measurement section should be possibly long. However, it may not be excessively long, as the tearing force will exceed the tensile strength of the core and lead to it breaking. Therefore, the measurement length $(L)$ was proposed to depend on the cord diameter in accordance with the relationships presented in Table 2.

Table 2. Selection of the measurement length $(L)$ depending on the cord diameter

\begin{tabular}{|l|c|l|c|}
\hline \multicolumn{1}{|c|}{$\begin{array}{c}\text { Cord diameter } \\
{[\mathrm{mm}]}\end{array}$} & $\begin{array}{c}\text { Measurement length } L \\
{[\mathrm{~mm}]}\end{array}$ & \multicolumn{1}{|c|}{$\begin{array}{c}\text { Cord diameter } \\
{[\mathrm{mm}]}\end{array}$} & $\begin{array}{c}\text { Measurement length } L \\
{[\mathrm{~mm}]}\end{array}$ \\
\hline Up to 4.5 & 50 & between 7.5 and 8.5 & 90 \\
\hline Between 4.5 and 5.5 & 60 & between 8.5 and 9.5 & 100 \\
\hline Between 5.5 and 6.5 & 70 & between 9.5 and 10.5 & 110 \\
\hline Between 6.5 and 7.5 & 80 & above 10.5 & 120 \\
\hline
\end{tabular}

The tests were performed for thirteen conveyor belts, observing the measurement lengths $(L)$ provided above. The test specimens were both the cords obtained from the belts and the corresponding new cords. The cords had various diameters and constructions. Fig. 6 shows the test results of core adhesion to the outer strands for the new cords, and Fig. 7 shows the results for the new cords and for the cords vulcanized in the belt. In the case of the new cords, the unit tearing force of the core from the outer strands can be observed to depend on the diameter and the construction of the cord. The greater the cord diameter, the lower the adhesion of the core to the strands. This 
phenomenon is related to the fact that in the case of small-diameter cords, the outer strands along the measurement length have a greater number of contact points than in the case of larger-diameter cords. The same observation is confirmed by the result for the $1 \times 19+7 \times 7$ cord, which is significantly higher than for the cord of identical diameter but a $7 \times 19$ construction. Also, in the case of cords obtained from the belt the unit force required to tear the cord core from the strands depends on the cord diameter - the greater the diameter the higher the test result. The increase is substantially greater than the increased measurement length would suggest. This phenomenon is due to larger empty spaces between the strands of the larger-diameter cords being penetrated with rubber during the vulcanization process.

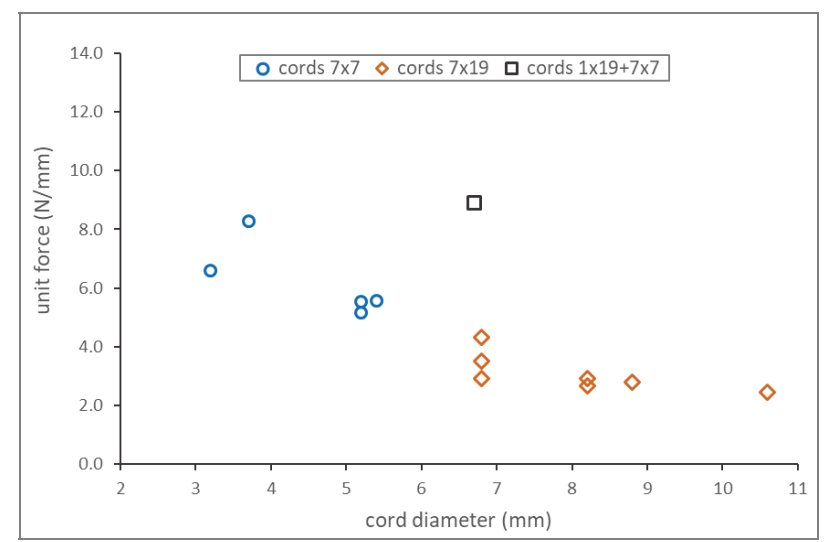

Fig. 6. Test results of adhesion of the core to the strands for the new cords

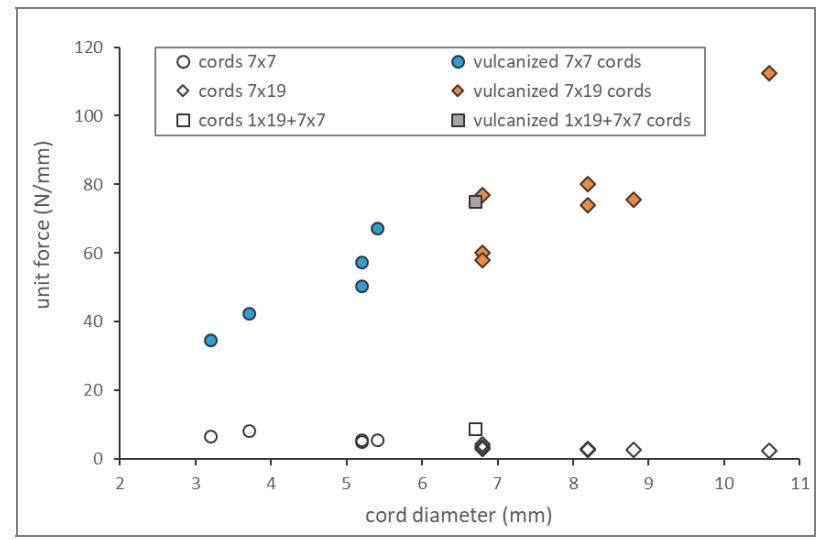

Fig. 7. Test results of adhesion of the core to the strands for the new cords and for the cords obtained from belts 


\subsection{CRITERION FOR EVALUATING STEEL CORD PENETRATION WITH RUBBER}

In the case of new cords, adhesion of the core to the strands depends on the cord diameter and construction, and for this reason when testing the adhesion in the vulcanized cords, the initial state of the adhesion differs. Therefore, the indicator of steel cord penetration with rubber $\left(\Delta F^{\prime}\right)$ is proposed as as a difference between the unit core tearing force for the cord obtained from the belt $\left(F_{v c}^{\prime}\right)$ and the unit force for the new cord $\left(F_{n c}^{\prime}\right)$. A question then appears regarding the choice of an evaluation criterion for the indicator, whose value will depend not only on the described phenomenon but also on the length of the tested specimen. As the measurement length $(L)$ was proposed to depend on cord diameter, the criterion for evaluating indicator $\Delta F^{\prime}$ can justifiably also depend on cord diameter. Therefore, indicators of cord penetration with rubber $\Delta F^{\prime}$ were identified in relation to cord diameter $(d)$ for all of the tested conveyor belts and shown in the form of a graph (Fig. 8). The results were arranged in series according to the rubber compound used in the belt. The trend lines were described with linear equations. The observations of the degree of cord cover with rubber, which was performed during the tests, and test results served as a basis to judge that the values of indicators $\Delta F^{\prime}$ in the tested belts are correct. Therefore, the line of the limit values was drawn below the identified values of indicators $\Delta F^{\prime}$ (Fig. 8 - continuous line), with an equation $y=8 x-1$.

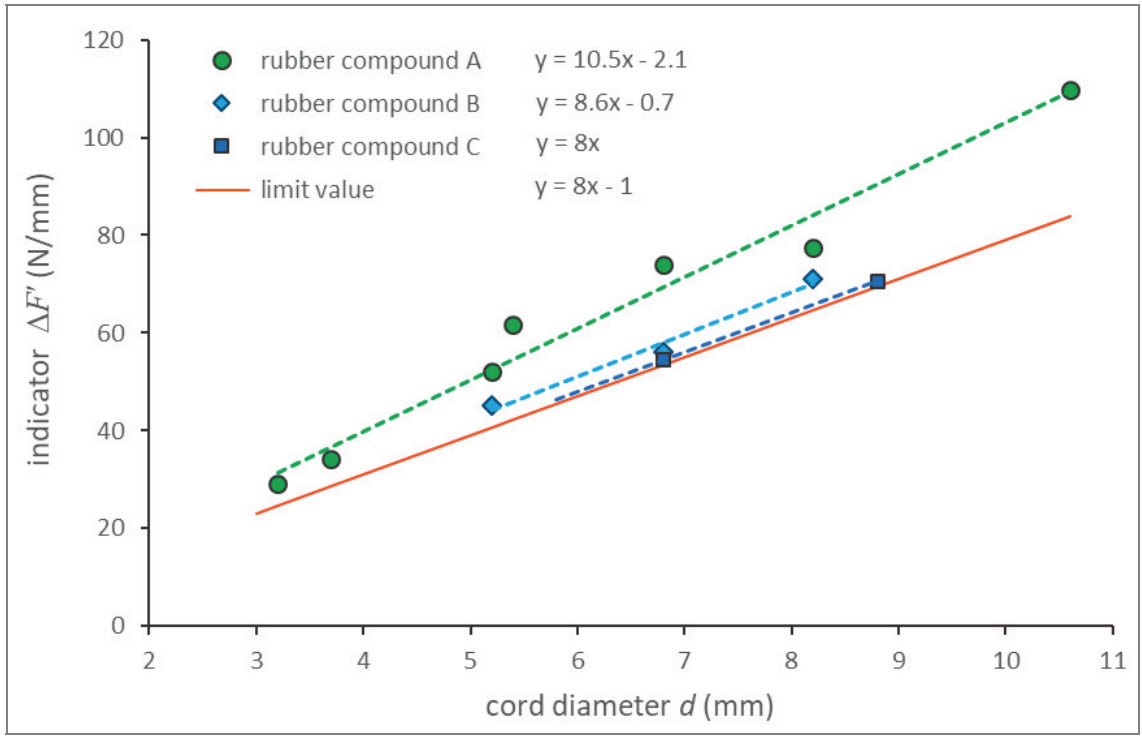

Fig. 8. Indicator of steel cord penetration with rubber $\Delta F^{\prime}$ in relation to cord diameter $d$ 


\subsection{TEST PROCEDURE}

Test results should be of acceptable accuracy, repeatability and reproducibility. For this purpose, the following procedure should be observed:

1. Obtain steel cords from the conveyor belt and clean them from rubber. Prepare a minimum of five samples having lengths equal to the sum of the measurement length $(L)$ as in Table 2 and the lengths of the two test specimen clamp parts $(2 \times 100 \mathrm{~mm})$. Seize the ends of the measurement length $(L)$ with copper wire $0.8 \mathrm{~mm}$ in diameter in order to protect them against untwisting during both the preparation of the clamp parts and the tests. The seizings should comprise five turns and be part of the measurement length $(L)$. Untwist the outer strands on both clamp parts of the test specimen and cut the core strand on one of the ends at a distance of max. $15 \mathrm{~mm}$ from the measurement length. Follow the same procedure in preparing a minimum of five test specimens from new cords.

2. Condition the specimens and test them at a temperature of $23 \pm 2{ }^{\circ} \mathrm{C}$ and in a relative humidity of $50 \pm 5 \%$ or at a temperature of $20 \pm 2{ }^{\circ} \mathrm{C}$ and in a relative humidity of $65 \pm 5 \%$. The conditioning time should be a minimum of six hours.

3. Place the test specimen in the testing machine, and secure the core strand in a clamp on one side and the outer strands in a clamp on the other side. The clamped outer strands should be in the shape of the letter V, at an angle of approximately $15^{\circ}$.

4. Subject the specimen to tensile load at a speed of $25 \mathrm{~mm} / \mathrm{min}$ until the core strand leaves the measurement length. Divide the recorded force $(F)$ in newtons by the measurement length $(L)$ in millimeters in order to find the unit core tearing force. If the result differs from the median by more than $10 \%$ for cords from the belt and by more than $15 \%$ for new belts, the result should be rejected and instead additional three specimens should be tested. Calculate an average value for all of the specimens.

5. Calculate the indicator of steel cord penetration with rubber:

$$
\Delta F^{\prime}=F_{v c}^{\prime}-F_{n c}^{\prime},
$$

where:

$F_{v c}^{\prime}$ - average value of the unit core tearing force for cords obtained from the belt, in newtons per millimeter,

$F_{n c}^{\prime}$ - average value of the unit core tearing force for new cords, in newtons per millimeter.

The value of indicator $\Delta F^{\prime}$ should meet the following condition:

$$
\Delta F^{\prime} \geq 8 d-1,
$$

where $d$-steel cord diameter, in millimeters. 


\section{CONCLUSIONS}

The penetration of rubber into steel cords during the vulcanization process of conveyor belts is a positive and a desired phenomenon. Filling of the empty spaces in the cord provides a good protection against the potential spread of moisture and corrosion inside the cord. The presence of rubber between the strands limits their direct contact, having a positive influence on the cord life. However, the most significant advantage of rubber compound penetrating into the cord lies in the increased strength of the cordrubber adhesive connection. Therefore, the degree to which the empty spaces between steel cords are filled with rubber is of significance for the reliable operation of a conveyor belt.

Current standards do not describe the tests and evaluation of steel cord penetration with rubber in conveyor belts. The proposed test method, based on identifying the adhesion of the steel cord core to the outer strands, is reliable and useful for a wide range of cord diameters and constructions on condition that tests of cords obtained from the belt are accompanied with tests of new cords. The proposed indicator $\Delta F^{\prime}$ is a quantitative measure primarily of the cord penetration with rubber, but also, to some extent, of the adhesive strength of the rubber-metal connection. However, this strength should be tested with the method described in ISO 7623:2015. The indicator $\Delta F^{\prime}$ is correlated with the cord diameter, and therefore the proposed criterion for evaluating cord penetration with rubber also depends on the cord diameter.

\section{ACKNOWLEDGEMENTS}

The authors express their thanks to WOLBROM Conveyor Belt Factory SA and Sempertrans Bełchatów for providing several sections of the conveyor belt with steel cords and a set of new steel ropes used in these laboratory tests presented in this article.

\section{LITERATURE}

BAJDA M., BŁAŻEJ R., JURDZIAK L., 2016, A new tool in belts resistance to puncture research, Mining Science. 2016, Vol. 23, pp. 173-182, https://doi.org/10.5277/msc162314

BŁAŻEJ R., JURDZIAK L., KOZŁOWSKI T., KIRJANÓW A., 2018, The use of magnetic sensors in monitoring the condition of the core in steel cord conveyor belts - Tests of the measuring probe and the design of the DiagBelt system, Measurement, Vol. 123, pp. 48-53, https://doi.org/10.1016/ j.measurement.2018.03.051

BONNERIC M., AUBIN V., DURVILLE D., 2019, Finite element simulation of a steel cable-rubber composite under bending loading: Influence of rubber penetration on the stress distribution in wires, Measurement, Vol. 160, pp. 158-167, https://doi.org/10.1016/j.ijsolstr.2018.10.023

DOBROTĂ D., 2013, Adhesion degradation of rubber and steel insert for conveyor belts, Journal of Adhesion Science and Technology, Vol. 27, Issue 2, https://doi.org/10.1080/01694243.2012.701511

HARDYGÓRA M., WACHOWICZ J., CZAPLICKA-KOLARZ K., MARKUSIK S., 1999, Taśmy przenośnikowe, Wydawnictwa Naukowo-Techniczne, Warszawa. 
JAYASEELAN S.K., VAN OOIJ W.J., 2001, Rubber-to-metal bonding by silanes, Journal of Adhesion Science and Technology, Vol. 15, Issue 8, https://doi.org/10.1163/15685610152542397

KRAKOWSKI M., 2017, Badania wyrywania rdzenia linki stalowej jako miary penetracji linki mieszanka gumowa dla różnych rodzajów linek, Praca dyplomowa (niepubl.), Wydział Geoinżynierii, Górnictwa i Geologii PWr, Wrocław.

PYPEĆ P., 2016, Badanie wyrywania rdzenia linki stalowej jako miara penetracji linki mieszanka gumowa, Praca dyplomowa (niepubl.), Wydział Geoinżynierii, Górnictwa i Geologii PWr, Wrocław.

REZAEIAN I., ZAHEDI P., REZAEIAN A., 2012, Rubber adhesion to different substrates and its importance in industrial applications: a review, Journal of Adhesion Science and Technology, Vol. 26, Issue 6.

RZYMSKI W.M., WŁÓKA M., GRZEŻÓŁKOWSKA-ROSIAK T., 2005, Łączenie elastomerów z metalami, Polimery, nr 7-8, https://dx.doi.org/10.14314/polimery.2005.530

Broszura Vattenfall, 2004, Kernlitzenausreisskraft, (materiał niepublikowany).

ISO 7623:2015. Steel cord conveyor belts - Cord-to-coating bond test - Initial test and after thermal treatment. 